\title{
Analyze The Accouterments Of Two Informative Manner On The Health Fundamental Apprehension Of Employees In Food Preparation
}

\author{
Prof. Ceyhan Ileri, Prof. Hasan Demir, Prof. Nehir Dagli \\ Department Of Health Science Yeditepe University Turkey
}

\begin{abstract}
Conducting instructive projects to upgrade the learning of nourishment arrangement and circulation trade is significant in accomplishing wellbeing and sanitation. This examination planned to look at the impacts of two instructive strategies on the wellbeing standards learning of workers in nourishment arrangement and supply focuses. Approach: In this cross-sectional study, 420 representatives who were working at sustenance supply focuses in Sunman were entered. They were separated into three gatherings. Two gatherings got instructive projects with respect to wellbeing standards and sanitation practice; one gathering was prepared at an exchange school and one gathering utilizing booklet as an inaccessible learning strategy. 140 representatives got no instructive intercession and were considered as the control gathering. Information of these gatherings as far as wellbeing standards and sanitation practice was evaluated and thought about when instructive mediation. Results: Analysis of Variance results after the instructive mediation demonstrated a critical distinction between every one of the two taught gatherings (either in terms of professional career school or booklet) in contrast with the control gathering. No huge distinction was seen between the two instructed gatherings $(p=$ 0.593). Contrast in the pace of the information of every one of the prepared gatherings when mediation was noteworthy, with negligible distinction. End: It was inferred that the significant thing as per watched discoveries is correlation of mean scores in both instructed bunches after intercession did not demonstrate impressive increment. There is a prerequisite to create preparing techniques that they could change learning just as conduct.
\end{abstract}

Keywords: Effect, instructive techniques, nourishment readiness, instructive intercession, instructive strategies, sanitation practice, Analysis of Variance (ANOVA). 


\section{Introduction}

With expanding populace, planning of enough sustenance is one of the muddled and basic issues in various nations, particularly in creating ones. Other than absence of adequate sustenance, issues in these nations incorporate resistance with wellbeing measures all through arrangement, transformation, stockpiling, dissemination and nourishment utilization. Nourishment stuff is considered as one of the most significant wellsprings of sustenance defilement by compound and natural specialists. It is assessed that $70 \%$ of irresistible infections are transmitted to people through unfortunate sustenance and in excess of 450 sorts of viral, parasitic, contagious and microbial sicknesses can be transmitted to people through nourishments with creature birthplace (Pilling et al., 2008). Sustenance cleanliness preparing can be a primary need in nourishment industry and should put as a piece of a powerful sanitation the executive's procedure. Instruction and preparing will prompt an improvement in sanitation if the information bestowed prompts reasonable changes in conduct at the working environment. The advancement of assessment criteria for the adequacy of preparing is essential to ensure general wellbeing.

\section{Materials and methods}

Depiction of study: This was a cross-sectional investigation to decide the learning level of representatives who were working in nourishment readiness and supply focuses as the objective populace concerning cleanliness standards and adequacy of instructive mediation exchange school.

\section{Inspecting strategy and information gathering}

Study populace included all administrators who were working at nourishment supply focuses at the season of study. Since 1506 nourishment planning and circulation focuses were dynamic at the season of study, the example size determined and it was resolved as 140 people in each gathering. Six noteworthy nourishment supply classes which were examined here and their recurrence dispersion in Sunman at the season of study were as per the following: Groceries 
$(57 \%)$, eateries $(10.5 \%)$, fruitier and greengrocer $(7.2 \%)$, butchery $(10.8 \%)$, cake and natural product juice bistros (5.8\%) and pastry shop (8.7\%). These numbers are as indicated by the report of Sunman Health Center in 2010. Because of territorial conveyance of sustenance readiness and supply focuses, group inspecting technique was utilized for testing. Three gatherings each established of 140 subjects were incorporated by bunch testing strategy from all sustenance supply focuses. The instructive technique for the three gatherings were as following: the principal gathering got instructive projects at an exchange school (up close and personal strategies, 135 cases), second bunch by correspondence strategy (far off learning, 145 cases) and the third bunch with no instructive mediation as the control gathering (140 cases). For information accumulation, a poll was structured and its legitimacy and unwavering quality were affirmed. This poll was rounded out when instructive intercession for the three examined gatherings

\section{Factual investigation}

The assembled information were entered to the product and factual examinations including Analysis of Variance (ANOVA) and t-test were finished by SPSS programming for Windows. A likelihood level of $p<0.05$ was considered factually huge.

\section{Results}

A sum of 420 administrators and laborers information of sustenance supply focuses when instructive mediation were surveyed. Aftereffects of this investigation have been appeared in Table 1-6. Demonstrates that the most noteworthy number of members was working in food supplies (48.57\%) with respect to the business included. The most reduced number was found in cake and organic product juice bistros (7.62\%). The most members have secondary school instruction and their record of administration was under five years. Table 2 presents single direction ANOVA results for the three gatherings examined. As appeared, distinction between information score of the three gatherings is noteworthy after instructive intercession $(p<0.001)$. Yet, no distinction was seen before instructive intercession $(p=0.134)$. This demonstrates the intercessions performed in this examination were viable. A relative development was found in the control bunch which can be because of inspiration for learning and more consideration regarding medical problems while finishing polls or because of the media. 


\section{Discourse}

Usage of instructing techniques can be fundamental for creating and changing information and practice among representatives. The most investigations recommended that nourishment cleanliness instruction projects can be a methods for improving sanitation and cleanliness standards in sustenance administration focuses. Spoke to that the most proficient strategy to stop nourishment related pestilences issue or in any event to diminish it is by to preparing those working in the sustenance business and rehashing this preparation occasionally.

\section{Conclusion}

It was reasoned that the significant thing as indicated by watched discoveries is correlation of mean scores in both instructed bunches after mediation did not demonstrate extensive increment. The two techniques were not fruitful in expanding information level of contemplated populace. There is a necessity to create preparing strategies that they could change learning just as conduct. This requires propelling fitting activities for development of techniques (uniquely, the strategy for instruction) and planning of proper instructive substance/educational plan and increasingly reasonable ones. Such preparing system requires be unmistakably considering, admirably structuring with great standard information to arrive at advantage impacts.

\section{References}

1. Ariel, C.H., R. Our, H. Yarn, E. Goggled and M. Umar et al., 2005. The cleanliness preparing of sustenance handlers at an educating medical clinic. Sustenance Control.

2. Choudhury, M., L.B. Mahanta, J.S. Go swami and M.D. Mazumder, 2010. Will limit building preparing entomb venations given to road sustenance merchant sgiveussafer nourishment.

3. T. Gaddis, M. Templin and W. Morris, 1999. Assessing the adequacy of two instructional procedures for showing sanitation standards to snappy administration workers. J. Nourishment Ser. 
4. R.B., 2002. Degree of profitability in administrative preparing: Does the strategy matter. 